\title{
Experiencing Liveness of a Cherished Place in the Home
}

\author{
Jinyi Wang \\ Mobile Life \\ (a) Stockholm University \\ Borgarfjordsgatan 12 \\ 164 07, Kista, Sweden \\ jinyi@mobilelifecentre.org
}

\author{
Mudassar Ahmad Mughal \\ Mobile Life \\ (a) Stockholm University \\ Borgarfjordsgatan 12 \\ 164 07, Kista, Sweden \\ mamughal@dsv.su.se
}

\author{
Oskar Juhlin \\ Mobile Life \\ (a) Stockholm University \\ Borgarfjordsgatan 12 \\ 164 07, Kista, Sweden \\ oskarj@dsv.su.se
}

\begin{abstract}
Liveness, as discussed in HCI and in media studies, focuses on an intriguing and beloved experiential quality that can influence new forms of video applications. We suggest a shift from accounts of liveness in "events" to liveness in ambient media for home décor by designing a system called TransLive that exploits the "magic" of mediatizing the "now" at a distant and cherished place. We present an interview study including four families, who experienced the system for two weeks each in a concept apartment setting. It shows how immediacy and unpredictability provide compelling experiences. Authenticity and engagement, which are previously considered as inherent qualities in live media, instead occur in the context of use. Finally, the experience of transcendence triggered by slow and continuous video streams open up a new design space of liveness. Thus, not only do we take inspiration from liveness theory, but we also need to redefine it.
\end{abstract}

\section{Author Keywords}

Liveness; mobile webcasting; ambient media; design; home

\section{ACM Classification Keywords}

H.5.2. [Information interfaces and presentation (e.g., HCI)]: User Interfaces.

\section{INTRODUCTION}

Liveness is important for people who experience it, as the "now" brings a "magical" quality [34]. Understanding the intriguing, but somewhat escaping, characteristic of it has been a longstanding concern in the field of media studies [11]. Different from traditional media, e.g. live programs on $\mathrm{TV}$, the advances of mobile cameras and sensors make live contents more accessible for both consumption and production, which opens up new territory for personalized liveness experiences [4,27]. The field of Human Computer Interaction (HCI) shows an increasing interest in the

Permission to make digital or hard copies of all or part of this work for personal or classroom use is granted without fee provided that copies are not made or distributed for profit or commercial advantage and that copies bear this notice and the full citation on the first page. Copyrights for components of this work owned by others than ACM must be honored. Abstracting with credit is permitted. To copy otherwise, or republish, to post on servers or to redistribute to lists, requires prior specific permission and/or a fee. Request permissions from Permissions@acm.org.

TVX'15, June 03 - 05, 2015, Brussels, Belgium

Copyright 2015 ACM 978-1-4503-3526-3/15/06 ...\$15.00

http://dx.doi.org/10.1145/2745197.2745198 experiences of liveness [19], which promises to open up new design spaces where the experiencers are offered with "the real sense of access to an event in its moment by moment unfolding" [34].

For example, there are potentials to design for liveness experiences beyond the understandings of it articulated in contemporary theoretical accounts, e.g. if taking away its "event" character and situating liveness in the ambience. Notably, the concept of "liveness" inspires emergence of new applications in a different way than the concept of "real time". The former emphasizes experiential qualities, and the latter highlights time constraints, i.e. between an action and system response. Liveness is an interesting concept since appreciating the "now" is a heterogeneous experience, rather than a distinct time measure. Live is also interesting as a media broadcast format and viewing practice, which evokes conglomerated experiences such as immediacy and authenticity.

We report the findings from the initial user study of TransLive, a system we have designed and developed that situates the liveness experiences in a domestic environment and positions ambience and aesthetics in the centre (see Accompanying Video). TransLive was deployed in the context of a "concept apartment", i.e. an ordinary apartment in a residential building furnished and maintained by the research department at a European furniture manufacturer. We interviewed four adult individuals, each of whom lived in the concept apartment with their family and experienced the system for two weeks. We found liveness, understood as experiences of immediacy and unpredictability, provided compelling experiences. The study extends the understanding of liveness experiences by showing that continuous live content presented in an ambient and aesthetical way may encourage a new type of engagement given the context of use; and that authenticity is not an inherent quality in the live media, but occurs through the actions of acquiring authenticity. We also discovered transcendence as a quality of liveness, unarticulated in previous research, which seems to bring an important experience in the everyday life.

In the following, we motivate the attention to liveness by drawing a technological landscape where it becomes a relevant and timely concept, and look at how liveness experiences are discussed within $\mathrm{HCI}$ in relation to 
terminologies well developed in media studies. Then we describe in detail our study and findings, which leads to the discussion of a more nuanced understanding of liveness.

\section{MOTIVATION AND BACKGROUND}

Real time video, distributed over mobile networks, becomes increasingly abundant and cheap, making the combination of mobile webcasting and ambient video possible. The ubiquity of camera phones and consumer-level digital cameras have brought a great anticipation in public discourse of how new live video services and new forms of use would emerge and become everyday practice among non-professionals [1,35]. Previous research has identified a number of general characteristics that make video production challenging and hampers its use, such as required editing, difficulties in finding and capturing relevant content $[22,25,38]$. With real time mobile webcasting, these problems are emphasized further [22,23]. In all, the use of mobile webcasting is in its infancy and new ways of viewing live videos are emerging.

One way is to present real time videos in ambient format in domestic settings, as the combination of liveness and ambience may open up new spaces for producing and experiencing live videos. Ambient video [5] is defined as a form of art presented on high-resolution screens [4,6] showing continuous, slow and aesthetically interesting content such as the changes occurring in sceneries of nature [6], which is only viewed casually.

\section{Liveness in media studies and in $\mathrm{HCl}$}

The focus on liveness, in the suggested format presented above, is influenced and motivated by its long-standing and continuous success in traditional TV and radio. As the media theorist Scanell argues, there is a "magical" quality in the temporal now of live broadcasts [34].

In recent years, there has also been a concern within HCI to account for liveness experiences [19]. Various accounts of liveness are emerging but somehow scattered. Technical research (e.g. [21,28,29]) is usually occupied with achieving media presentation occurring as close in time to the captured content as possible i.e. "real time". Works in art, music and performance have investigated various experiences associated with such temporal adjacency, beyond the studies of live webcasting of video (e.g. $[18,20,37])$. Design-oriented research projects touch upon liveness experiences without explicitly stating it (e.g.[13,15]). Given this interest, we are motivated to align and articulate liveness experiences existing in HCI research with the theoretical concepts that are well established in the area of media studies, in order to investigate its potentials in design. In the following, we account for liveness in relation to a set of experiential qualities conceptualized in media studies, namely immediacy, unpredictability, engagement and authenticity.

Immediacy: Liveness is considered as an immediate experience, as it occurs in the "now" [2]. It works as an extension of human vision, enabling instant access to distant events as they unfold. Research in HCI is interested in the topic, although conceptualising it in various ways. Video chat is seen to have the quality of liveness, as it allows immediate connection with families and friends remotely [30]. In the study of the photograph app Instagram, Weilenmann et al. discuss how immediacy, or real-time distribution, makes it different from other photosharing services [39]. A design project pushes the liveness experiences of photo-sharing further by instantly and continuously displaying all the published Instagram photos from a chosen area in a city [42]. Real time data is also used for creating liveness experiences, e.g. the so called "Threshold Devices" gather real time data from a home's surroundings, such as blowing wind and passing-by airplanes, and present them in an aesthetic way in the homes [13]. Immediate access to information surrounding the home, enable the inhabitants to experience liveness from the outside. In all, immediacy, or the sense of now, is essential for various liveness experiences.

Unpredictability: Live content potentially generates experiences of the unexpected as a combination of unpredictability and spontaneity [2]. There is an anticipation that something unplanned might happen in the viewing experience of liveness. Hook et al. investigates a non-mediated event, where the performers and the audience are co-located, and how the liveness experience is diminished if part of the creative work is pre-manufactured in advance of a performance [18]. For example, co-present experiences of "laptop"-generated VJ performances feel less "live" than traditional live concerts. Liveness includes some sort of improvisation, responsivity and uniqueness [7,26]. The unexpected character of liveness was also discussed in Gaver's design of the Video Window, in which he attached a camera on the outside wall of his home that was continuously streaming the video to a monitor on his bedroom wall [16]. He described extensively how unanticipated weather changes, e.g. raindrops or snowflakes landing on the camera, brought aesthetically pleasing experiences in viewing the live video [16]. The unpredictability is thus crucial for liveness experiences.

Engagement: Liveness often comprises engagement among viewers such as during concerts, performances and sports events. The audience have an emotional connection, i.e. an "despatialised simultaneity" with the event and its participants [36]. The presence of the audience also creates the sense of liveness, as a performer's awareness of the audience is often fundamental to the flow of the performance [33]. In an interactive dance performance, the researchers even involved the audience in the creation of the liveness experiences [12]. The interactive performance can only be fully experienced when the audience's active engagement is achieved [12]. The understanding of liveness in relation to engagement appears to emphasize its "event" character, where co-presence and co-location is key to the experiences. This view indicates that the level of 
engagement is high. It implies to fully engage in liveness experiences is something special that stands out from "everyday life".

Authenticity: Liveness is also associated to experiences of trust and authenticity. It seems that liveness comprises an experience of realism, i.e. as being there while something is really happening. The almost immediate transmission decreases the possibilities to manipulate the media through post-processing, or censoring content. However, the structure of the camera and production setup means that there are ways that the media content can be pre-computed into the system to give a viewpoint that is not quite as neutral as it may appear (see [27]). In HCI, the relation between liveness and authenticity has been a concern. It is argued that co-present performers and audiences at a live event provide inherent authenticity, which might be lost if it is mediated. Co-present mediatization could be interesting if it increases engagement by parallel activities [6]. Jacobs et al. discuss the balance of data authenticity and audience engagement in liveness [20]. In a study of an interactive artwork, an audience was presented with scientific climate change data through live connection between two remote forests. The artists gained the public's trust by creating various "smoke and mirrors" effects [20]. Research in HCI recognizes authenticity as an important aspect of liveness experiences mediated through technology. But the detailed ways in which such experiences occur lack in articulation. The ubiquity of mobile cameras, sensors and networks makes real time media more ubiquitous. Thus, there is a need for an increased understanding of how this map to authenticity in liveness experiences.

In sum, the "magic" of liveness has already been identified within the studies of traditional broadcast media. With the emergence of technology for personalized media production and consumption, so has the interest in liveness experiences increased within HCI. The latter interest is both recent and fragmentary, which motivates further investigation.

\section{METHODOLOGICAL APPROACH AND SETTING}

This paper focuses on understanding people's experiences with liveness through an interview study of the TransLive system. The system per se was created as a way to explore the opportunities to extend liveness as design space beyond the "event" [31]. It was generated following the Research through Design (RtD) approach [41] in order to investigate liveness experiences through design instantiations. RtD has become a widely adopted approach within HCI as it embraces the practice-based nature of design investigation $[14,40]$, where the knowledge should be "generative and suggestive" [14]. By adopting RtD, our approach can be seen as twofold: 1) the practice-based design exercise that examines the idea of combining personalized mobile webcasting and its representation in an aesthetical and ambient way; and 2) the focus on liveness experiences that opens up the design space of bringing the "magical" quality of liveness in the everyday. The home is then an instance of the "everyday" as opposed to the "event".

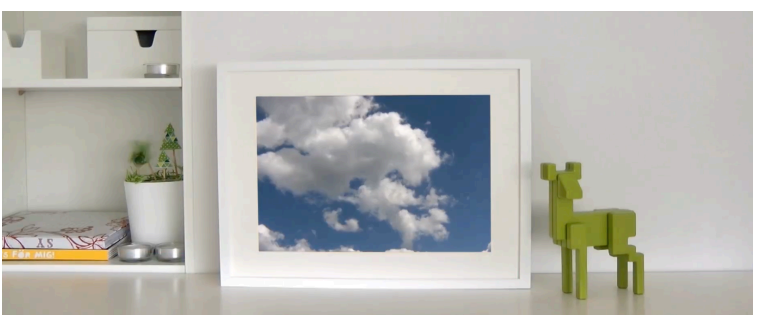

(a)

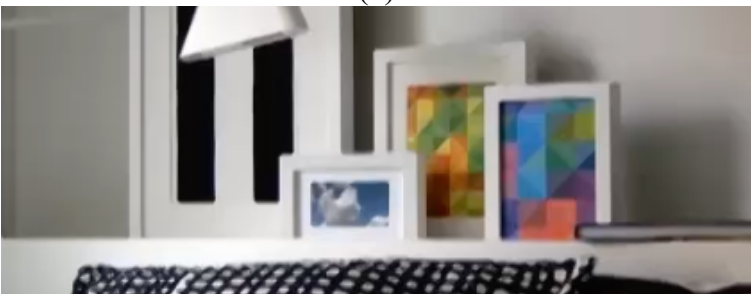

(b)

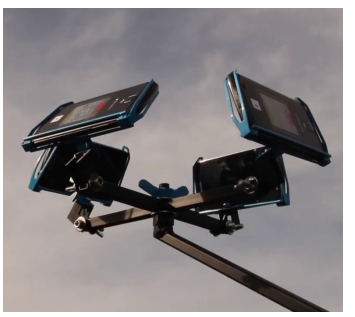

(c)

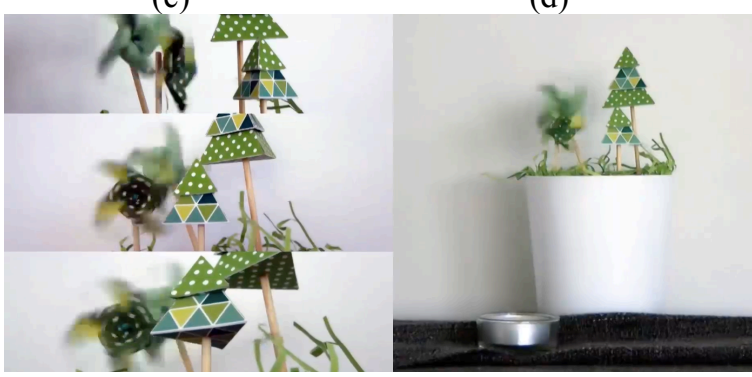

(e)

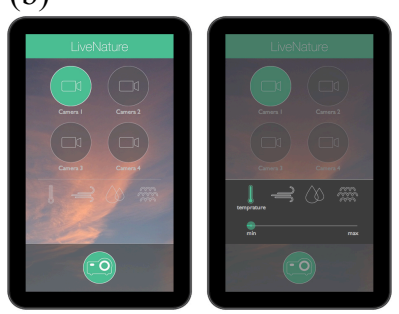

(d)
Figure 1. (a) Large Display (b) Small Display (c) Mobile Cameras (d) TransLive App (e) Windmill Ornament

\section{TransLive}

We refer to a cherished place as a geographical location to which one has a strong emotional attachment. TransLive is a system that intends to bring the sense of such a place into the home by presenting the views and the weather live in an ambient and aesthetic way that fosters reveries. The design process includes three ethnography studies of people's love for their cherished places, the design vision emerged from the fieldwork, technology context and aesthetics in home, and an iterative process from ideation, prototyping and pilot tests, to the resulting system (details of the design process have been reported in [31]). A set of artefacts, collectively seen as the interface of TransLive, are designed and built to support the live connection to the cherished places (see Accompanying Video). The interface consists of four small displays and a 20-inch large display attached in wooden 
painting frames, as well as a handcraft windmill ornament. The four small displays (Figure 1-b) show the real time videos streams captured by four water-resistant mobile phone cameras installed at the cherished place. The mobile phones are attached to a flexible stand that we designed and built in order to make the cameras angles adjustable (Figure 1-c). The large display (Figure 1-a), connected to a server, shows a selected live stream video and allows the weather from the cherished place to influence its visual style. For example, the changing wind speed makes the video appear blurry, which mimics a camera lens trying to find its focus in the blowing wind. The weather data, e.g. temperature, wind speed and direction, are captured by a weather station co-located with the mobile cameras. Both the video and the weather data were sent to the home via $4 \mathrm{G}$ networks to ensure high quality and smooth transmission. We also developed an Android app (Figure 1-d) for selecting the video and weather visualization. The windmill ornament spins in relation to the wind from the cherished place (Figure 1-e). A hidden fan, blowing to the windmill, is installed in the bottom of the windmill, connected to an Arduino Yun component and driven by the wind speed data from the weather station.

\section{Interview study}

The system prototype was deployed in the context of a "concept apartment", which is maintained by an international furniture company in order to evaluate novel concepts with potential users in a domestic environment for long-term use. It is situated at an ordinary apartment in a residential building in the city of Malmö in Sweden. The 100 -square-meter apartment has three rooms. Its interior is designed and furnished by the designers in the company with a strong brand identity. An interior designer from the company was also involved in the implementation process and acted as a stakeholder of both the company and future dwellers. The concept apartment context provided us, with our limited resources, an opportunity to evaluate the system with multiple families for a longer time. Ideally the participants should have installed the cameras and weather station at their cherished place by themselves. However, the current system implementation was still difficult to install and configure. Therefore, we asked where the participants' cherished places were and installed the input for them. The provision of a concept apartment allowed us to install the ambient displays and set up the configurations for one time although testing it with multiple families, which saved our time and resources. Even though the set-up provides initial user feedback, a concept apartment is not the participants' real home. To accommodate for this difference, the interior was designed to be casual and comfortable. Furthermore, TransLive was only one of three unrelated prototypes evaluated in the lab at the same time. This situation had put high requirement on the design and deployment [31]. It also limited the time and attention we could acquire from the participants.
We have predominantly considered adult individuals living with their family as main participants, instead of considering all family members as participants. Still, we recognize cherished personal belongings may relate to the families and have an impact on family lives [10]. The same applies to a personal cherished place when presented as a digital artefact in the home. Four participants were recruited by the property management company via posters in the neighbourhood, where the concept apartment was located. They were respectively invited to stay in the concept apartment with their family for two weeks during April to June 2014. Selecting four out of totally five adults provides a sufficient sample in the early phase.

Before arriving at the concept apartment, the participants were interviewed about their cherished places, where it was located and their feelings thereof. We then installed the mobile cameras and the weather station as close as possible to this place. The videos and weather data were then presented through the TransLive interface. The families were informed of the study and had full control over the usage of the system. As the idea was to design for ambient experiences that allow varied attentions, we chose not to request the participants to pay special attention to the displays or to keep a record of their experiences with the system on a regular basis. Instead, the focus was on how they experienced TransLive and what it might bring to their everyday lives. In the following, we briefly describe the respondents and their families with fictional names for anonymity concern.

Ron's Family: Ron moved to Malmö from Wales more than 12 years ago. He is a 43 year-old single father and lives with his 5-year old son. He has two teenage sons who stay with him every other week. Ron chose Beijers Park in Malmö as his cherished place, as he had "been there so many times in the past 12 years of living here". Thus, we contacted a company nearby and installed the cameras and weather station on their balcony facing Beijers Park direction. The installation was completed before Ron and his younger son moved in to the concept apartment.

Mia's Family: Mia is 33 years old and a single mother, living with her 5-year old son in Malmö city. She is from Sweden, but she has close relatives abroad. Mia also selected "Beijers Park" as her cherished place. Thus we kept the cameras and weather station in the same location.

Jane's Family: Jane is a 35 years old single mother living with her 9 years old son. She has two teenage children, who stay with her every second week. She is from Sweden and has many friends in the city. She loves the ocean and her cherished place is a harbour called "Västra hamnen", located west of Malmö. Before Jane and her son moved in the concept apartment, we reinstalled the cameras and weather station on the roof of an 8-floor building beside her selected location. During her stay in the concept apartment, Jane had her teenage children staying with her, occasionally 
had some friend visiting and organised a party in the apartment.

Ben's Family: Ben is 58 years old and living with his wife. They moved to Sweden and Malmö decades ago. Their children and grandchildren visit them every day. Ben also said that his cherished place was Västra Hamnen, where he often took the ferries and went for walks with his wife. We kept the cameras and weather station at the same location.

\section{Data collection and analysis}

On the last day of each family's two-week stay in the concept apartment, one interviewer visited the family to conduct a one-hour semi-structured interview with the main respondent. We adopted a semi-structured interview approach, as it is a commonly adopted approach in studying technology in the homes [17]. It is beneficial for making both experiences and interactions available at an early stage while preserving users' privacy. The interview questions focused on two themes: 1) the use of the system, e.g. when they looked at the displays and for how long, and if they discussed it with others at home; 2) the experiences, e.g. feelings and thoughts while seeing the cherished place from the displays, and if they remembered particular moments.

The interviews were audio-recorded with the participants' consent. The same routine was repeated for the four families. The first interview with Ron was done in English. The other three interviews were done in Swedish. We transcribed the interviews and translated the Swedish interviews to English. After transcribing and translating the interviews, a set of aggregated categories that brought out salient characteristics in the materials was developed. The aggregation was conducted following a qualitative approach [9,32], whereby themes were developed by attending to individual answers and comments, as well as to theoretical concepts of liveness.

\section{FINDINGS}

The analysis is focused on viewers' experiences related to previous liveness theory, as well as on particular experiences of TransLive as a form of ambient media.

\section{The instant access to the cherished place}

The TransLive system provided the participants with access to a remote and cherished place. It offers, similar to live television [2], an extension of human vision and provides viewers with instant access to the distant events as they unfold. All respondents appreciated seeing things unfolding as they occur. Different from engaging live TV from e.g. a sports event, the sense that something ordinary is happening and constantly changing seems to bring a calmly pleasant feeling. Both Mia and Jane described such experience as "pleasant" and "nice". Ben stated that it was "a pleasure", and he felt in "a relaxed mood" when looking at the displays, since the view of the sky and clouds were changing. For example, Ron enjoyed watching the shift of time between day and night. He liked "(to) see changes in the daytime and night time, and even three o'clock in the morning when it's quiet, it would bring the air". The participants also enjoyed looking at people, cars, boats and planes as they moved. Mia mentioned that her son enjoyed watching passing airplanes. Ben liked to watch "cars and drivers, when they drive". He enjoyed looking at people, which made him feel "myself being there". Jane enjoyed " $a$ feeling that something is happening." And she commented, "It's for real, it's live and it really exciting, because you know for yourself that it is something going on live that you are filming now".

The instant access to the unfolding events also enabled the participants to encounter moments of surprise, which were essentially just small happenings that brought a sense of the dynamics of the world. Most of the participants referred to such occasions. For example, Ben recalled that "I was looking [at the display, authors' comment] yesterday and then there was a boat passing by. You could see it on the screen there!" And Mia commented on how her five-yearold son liked to watch when airplanes and birds went by. Jane enjoyed looking at the boats by the harbour and had a growing attachment to it, "I was like, what has it [the boat, our comment] been doing there for so many days?" One morning, she found it was gone and shouted out loud, "wow, check this out kids, come and see, the boat is gone! It moves!" She also recalled, "One day, it was such a beautiful day, no clouds, really beautiful, and you could see the sun there in the camera, it was really nice".

The excitement of looking at something unexpected was also observed during the interviews per se. As the system was running during the interviews in the concept apartment, several participants were distracted by unexpected events on the displays. They interrupted the interviews and asked the interviewer to look at the displays. For example, Ben turned to the display and shouted out loud " $A$ bird!" while answering a question. Ron suddenly pointed to the cloud on the display, "It's nice, looking at that now! You can count how long it takes to move, that's quite interesting, isn't it! ... You can look at the screen now for a while to see, you now like, how long it will take for this little cloud to move, you know here, to move off the screen." Later during the interview, Ron saw a bird, and the excitement was triggered again, "Oh, there's a bird there!... That's great! I like that. I could sit here and count them. It only seems to be one at a time that goes by. Usually, there's a flock of them in there!" The participants seemed to enjoy viewing something unexpected on the display. Such enjoyment was provided by the experience of "now" and "unexpected", and the live content on the display had a quality of uniqueness compared to recorded videos. This finding is in line with media theory that liveness has a magic quality enabled by immediacy and the "unexpected".

In sum, the experience of the immediacy, i.e. looking at something perceived as happening "now", as well as the thrill of the unexpected seemed to transport itself from event-based live broadcasts to that of an ambient media. 


\section{Sporadic Engagement}

In previous articulations of liveness, it has been noted that the viewers are getting very engaged. Their focus and attention shift from the everyday to the broadcasted event. TransLive on the other hand envisions interaction with live broadcast that blends in everyday life, individually or with families and friends. The live connection to a cherished place is intended to become a subtle, ambient and pleasant element in the everyday life at home, and both individual and social viewing practices point towards that direction:

Individual viewing practices: All individual participants seemed to have paid varied attentions to the displays at different times of the day. Ron commented that the big display in the hallway caught his eyes every time he came in and went out of the apartment, especially when the light switches were off. Similarly, Mia enjoyed the display particularly in the evenings and nights when the lights were down, and she described this experience as "cosy". Both Jane and Ben commented that they liked looking at the clouds from the displays when they just got up in the morning. The duration of watching the screens varied too. Mia and Jane glanced at the display for just a few seconds when they passed by, while Ben enjoyed looking at the display for a few minutes and Ron preferred being able to look at the display constantly when he could sit down and relax. Ben's son came to visit while the interview was taking place; he described nicely the varied attentions the display afforded, "when you are going to the toilet or the kitchen, you pay attention to it (the big display hanging on the wall in the hallway), but it doesn't draw your gaze, as soon as you start looking at it, you start thinking, oh, I want to be by the ocean now!"

Looking together: All participants reported looking at the displays and talking about the views with their family members or friends, e.g., Jane said "I showed all my friends when they were here, and they got really 'wow'! They were like, is it live, where is it, how does it works... They thought it was awesome to have such a thing at home."

In sum, the TransLive system enabled a less engaged orientation to the media, as compared to live TV broadcasts of events, which could be described as "sporadic" [13]. The participants often paid varied attentions to the displays rather than being fully immersed during the viewing. They instead conducted repetitive and glance-based viewing. This type of interaction seems to encourage participants to embrace the liveness experiences in the everyday life over a long term. The system became part of their daily life in the sense that the families and friends of the participants were often involved in the interactions and the live content became a topic of conversation. In all, TransLive pointed to a new direction for designing liveness experiences, which allows for varied attentions, encourages sporadic interactions and enhanced the "low" but long-term engagement, which, in turn, enriches a new type of liveness experience.

\section{Authenticity}

In previous theory, liveness has been said to comprise trust and authenticity. However, the experience of TransLive engendered rather mixed experiences of this sort. Some did perceive the video streams as real rather than edited and the weather data as genuine even though they were interpreted and represented in an uninformative manner. Ben reported that he checked the weather through the displays before going out, "the weather outside, if I want to know I look at the screen". Similarly, Jane perceived the spinning windmill as an indication of the wind speed outside. She said that she had the windmill on "to get a feeling, to see the weather and the wind and so, if you should put on your jacket and so, or maybe I will not take my bike, because it's so windy". She added "I showed all my friends (the system) when they were here, and they got really wow, so before you walk out you can have a look at the weather".

Other participants displayed a degree of distrust of the authenticity of the media. Mia, Ron and Jane all commented that the media might be produced on other places than their individual cherished places. Ben presumed the cameras could have been installed in the cherished places picked by previous families who also participated in the study, "I have been here since the fourteenth of this month, and maybe it [the installation of the cameras, authors' comment] was from the other people living here?" Sharing the same concern, Ron repeatedly asked the interviewer if the camera was actually in his chosen park, in spite of the interviewer had confirmed so.

In all, authenticity is viewed as a given feature of liveness experiences in media studies. However, the study revealed some degree of complexity and paradox in relation to authenticity, i.e. the participants trusted streaming videos and weather data as authentic, but also expressed uncertainties towards the camera locations. The view of live as inherently authentic is here challenged by the emerging format of live content.

\section{Authentication work}

Since the viewers did not experience the media as authentic from start, it was obvious to observe the ways in which they approached the media to investigate its trustfulness. The participants displayed a set of strategies, which we term "authentication work", to examine the authenticity of the media.

Matching the digital with physical: The participants tried to match the digital content shown in the live video with the physical world as a means to investigate its authenticity. Such matching included identifying physical landmarks in the videos, and observing the synchronization of the video content and the physical world. Ron and Ben suggested providing recognizable visual references to identify the camera locations. Ben suggested pointing a camera to the landmark, "bo01 tower", at his cherished place. Ron suggested displaying some scenic features, e.g. "the grass and the river, the little pond there" in his cherished place to 
increase his trust. Jane commented the display showing the harbour felt "more real". She also compared the sky from her balcony with what was shown on the big display, and the similarity between them had reassured her that the location of the camera was close to her chosen location: "I sat on the balcony with a friend, and then it was this strange weather, suddenly it was sunny then it became cloudy a few times. I went here (to the big display in the hallway) and had a look at that screen, aha, it's going to be like that, there's a lot of clouds!"

Witness and authority: The need for reassurance was expressed by Jane's friends too when they had a party in the apartment. Jane shot a video with her mobile phone when she was telling her friends about the system. Her friends (about 15 people) asked again and again, "Is it real?" "Is it now?" "Is it live?" and "is it in Malmö?" She confirmed all the questions with confidence and showed the other camera views by switching them via the mobile phone app. Her reassurance was met with a shared "wow"-expression from the audience. Authenticity, in this case, is then achieved through some kind of "witness" or "authority", which is also discussed by Jacob et al.[20]. Jane's friends' inquiry about the state of media and Jane's response and then her friend's satisfaction, as discussed above, is tantamount to seeking testimony from a trustworthy eye witness and/or an authority.

Involvement in production: Some participants commented their involvement in the media production, i.e. to install the mobile cameras themselves, could be a way to increase the turst. We designed and built a flexible camera stand with that exact purpose in mind and intended to involve the participants in the installation. Due to technical and logistic constrains, we could not involve them in installing the cameras and weather station. However, the participants' comment confirms our idea of supporting personalized media production. And it also points out that authenticity can be achieved by involvement in media production.

In sum, the participants tried to get to the "truth" by requiring landmarks for identification; by checking the synchronization of the weather from the displays and from the outside; and by inquiring trusted "authorities" or reveal that authenticity should not be taken as given. Instead, authentication works should be considered and possibly designed for.

\section{Transcendence in time and space}

The views from the displays seemed to have the power to take the viewers' minds from the immediate domestic environment to the remote cherished places, or simply from here and now to there and beyond. As Jane put it: "you are inside, but...you are taking part of the outside." But the experience is more than being able to look outside. Looking at the displays seemed to trigger the viewers' memories, imaginations and dreams, e.g. good memories from the past, or something they used to do or could do, or the longing for the next trip. Ron described his experience as "(being) drifted away and thinking about home". Similarly, Mia imagined installing the cameras and weather station close to her beloved relatives in another country, so that she could see their place and the weather. With enthusiasm, Jane commented, "(I) start thinking of flying! I want to fly where you see clouds." Ben said he started imaging when seeing the images and the imagination felt like coming from inside. He further described the experiences, which demonstrated how his mind drifted away from the display, "I feel like I go inside the boat and inside the sea, because I like it, the clouds and the sea. Every two or three weeks I go to Helsingör. I see the clouds in the sea, and the boats, I like this. I take my wife. I want to go to Helsingör by boat, sometimes in my car. Sometimes I leave it in the parking lot, and we shop and eat." Ben's son also recalled that "once I saw it (the display) briefly, then I thought about airplanes. When it's cloudy and blue, you think about an airplane up there in the sky."

The accounts for liveness experiences in media studies tend to focus on highly engaging experiences of an event. At the same time, such experiences can be somewhat passive drawing on consumption of the live events. In our study, the participants seemed to have experienced their minds actively drifting beyond the content of the displays to different locations in time and space. This experience echoes a type of transcendence, which happens in environments that are familiar and considered with more affection or feelings of belonging [37], in other words, the cherished places. The drifting minds also indicated a sense of ease and effortless attention with less intense focus or engagement, similar to the transcendent experience when people are in nature. Liveness in previous research is understood as a means to induce the experience of an event as it is, whereas we extend this understanding by showing that TransLive triggers viewers' imagination and enables them to transcend their mind's eye through time and space.

\section{DISCUSSION}

We took a qualitative approach and presented detailed descriptions of a small number of families' experiences of the TransLive system for two weeks. Such limited approach still enabled us to obtain some insights into the participants' experiences over time and focus on articulating a nuanced understanding of the use of mobile webcasting in particular, and of liveness experiences in general. The understandings of liveness through our study showed both similarities and differences compared to previous research in media theory. Therefore, our approach does not only take inspiration from the theory, but also revisits and develops it. In the following, we reflect on immediacy, the liveness concept and broadly discuss a more nuanced understanding of liveness experiences.

\section{Restating the "magic" in an ambient setting}

Overall, our study of TransLive supported our idea of combining personalized mobile webcasting with its representation in an aesthetical and ambient way. The 
results indicated that the viewers' acquired liveness experiences of a cherished place in a domestic environment. The participants appreciated the connection with their cherished place and valued its immediacy and unpredictability. The sense of mediated sceneries happening "now" was positively regarded. Similarly, the system provided unexpected and unanticipated experiences of e.g. a boat leaving the harbour or a bird flying by. In a broad sense, our orientation to liveness, including immediacy and reality, seems both valuable and fundamental for the experiences. Existing approaches to experience liveness through user-generated webcasting could be extended beyond mediatizing events, to account for content of ambient nature. It may inspire further designoriented research with similar topics in HCI.

\section{Real time vs. liveness}

Since the concept of immediacy is fundamental to liveness, we need to consider why it is not enough to investigate the potential of getting inspiration and understanding the implications of "real time" applications. Some of the attention to liveness concept in HCI has also focussed narrowly on the benefits of immediacy [38], which is very close to conflating the concept with the notion of "real time". The concept of real time pinpoints measurable temporal differences between an action and system responses, whereas the experiences related to liveness are less easy to articulate. It seems to require a broader set of characteristics i.e. a conglomerate, as the same as it seems diffuse and heterogeneous. Appreciating the "now" is a heterogeneous experience, rather than a distinct time measure. The experience of "now" is plastic and might refer to a second, today or a year, or to mobility. The users of TransLive seem to experience immediacy when they identified movements of a boat or a bird, although with very different understandings of what "now" referred to. Live is also a media broadcast format and viewing practice, which evokes conglomerate experiences such as both immediacy and authenticity.

In media theory, liveness has been specifically associated with authenticity and something being "real". In HCI, it has been noted that the liveness experience decreases if the media, such as in a VJ-performance, is understood as premanufactured [18], disregarding how "real time" the digital animation might be. Liveness is still interesting, despite its somewhat evading meaning, since it is the experience that we intent to design for.

\section{Re-defining the Liveness theory}

Although the liveness concept is inspiring, we should not just accept it as is. We need to ensure that when we apply it to new domains, we also rethink the aggregated concept of liveness. In specific, our study reveals a need to revisit how existing categorisations such as that of the experiences of engagement and authenticity as part of the liveness conglomeration.
Sporadic Engagement: In media theory it is stated that live content is particularly engaging, which implies some sort of focused interaction between the viewer and the mediatized content. In our case, liveness content is accommodated in a domestic environment. It requires its physical form to be unobtrusive, in the sense that it doesn't grab attention and it blends in the surroundings aesthetically. The media representing the content should afford both glance-based and highly focused engagement. In our study, the participants enjoyed the location of displays in the hallway, which allowed them to experience the media upon passing by in-between rooms, and entering or exiting the apartment. But when the interaction was extended, the displays needed to be placed where the inhabitants hold their view for a prolonged duration, such as at the TV screen. Then the concept of locating the screens at the same place as other picture frames became problematic. Although the participants were engaged, it was in a very different sense that being highly aroused for a short period. We therefore understand engagement as blended into everyday life in the homes, in a way that allows varied attention. We also found the viewers having a tendency of sporadic and prolonged engagement over days and weeks with the system. Thus we refer to such engagement as "sporadic engagement", and we argue for a broader conceptualisation of engagement of liveness that includes sporadic engagement. The design of liveness experiences in everyday settings can encourage such engagement that is both sporadic and prolonged.

Authenticity work: The concept of authenticity, as discussed in media theory, also needs a revisit. Previous related works tend to see authenticity as a given feature in real time broadcasts. In our study, several participants raised a concern whether the media was live. At the same time, we identified practices through which the experience of authenticity increased e.g. matching, witnessing and producing. The uncertainties expressed by the participants, and the visible authentication work, pinpointed the fact that authenticity should not be taken as a given characteristic of real time media or live broadcasts, when designing for such experiences, especially in the era of "democratized" media production. The design of liveness experiences also needs to account for the authentication work. With the increase of user generated live content, we need to recognize that the questions of trustworthiness are much less settled compared to traditional TV and radio broadcasts. We also see an opportunity to design for authenticity work in order to embrace and expand liveness experiences.

In media studies, both engagement and authenticity have been conceptualised and understood as emerging out of the broadcast content, which is independent of the viewing context. In our study, we identify a form of sporadic engagement and authenticity work by focussing both on the content and the context of use. Both these extensions are of relevance to provide a nuanced understanding of liveness experience. A broader conceptualisation may also lead to an extended variation of liveness in design. 
Extending the list of Liveness Conglomerate Experience We identified a type of experience, namely transcendence, which has not been accounted for in theoretical conceptualisations of liveness. The participants not only enjoyed being able to see views of a cherished place, but also surpassed those views in their mind's eye. When looking at the clouds and the sky above their requested cherished place, they started thinking about good memories, other places far away, or plans for the future. In other words, they transcended the mediated connection to a remote place. The experiences of transcendence triggered by the surrounding objects are previously identified in other areas. Bachelard describes such experience as, "(the mind) flees the object nearby and right away it is far off, elsewhere, in the space of elsewhere" [3]. Katz [24] discusses another form of transcendence, which also seems relevant in the generation of liveness experiences. He describes how anger in road traffic is created partly when a driver transcends the available social situation and infers other problematic contexts (e.g. unemployment) that are not available to other drivers. In our study, liveness "transported" the participants' minds away from the mediated cherished place to elsewhere in time and space. Drawing on Katz, this activity contributes to emotion, and the system then contributes to making transcendence possible. Importantly, it does not happen in the system or in the mediated content, but as an associated activity by the viewer. In all, we argue recognizing transcendence emerged from liveness could inspire a new design space.

\section{Design Implications}

Although our focus is to develop a nuanced understanding of liveness on a theoretical level, some design implications emerged from the study. Firstly, more attention is needed on the design for authenticity works, e.g. to provide the users with logs or GPS data of the cameras. Secondly, sporadic engagement can be further encouraged to enrich the daily lives at home, e.g. different designs of ambient media and live content in forms of slow art. Furthermore, customization can be further developed, e.g. to enable close-ups or wider viewing angles.

\section{Reflection on Methodology}

Although open-ended design study, often referred to as field trial, is a commonly used method in HCI, it is also an approach that makes it hard to distinguish whether the results are derived out of experiencing the system, the positive experience of trying out something new, or the orientation to pleasing the evaluators by providing positive judgments [8]. Two weeks of experiencing the system may decrease some of the novelty factors, but the result must still be handled with caution. Furthermore, this initial user study is intended to generate more specific research questions. As discussed by Gaver, the aim of a study, in an early stage where the ambiguity and uncertainty is high and valuable, is to collect results that are suggestive and generative [14]. In this case, the design concept seems intriguing and suggests new design space for liveness experiences. However, it doesn't address specific questions such as if user experiences of live streaming change in between transmissions with high frame rate, e.g. video, and low frame rate, e.g. static image.

\section{CONCLUSION}

Our research aim has the ambition to both describe the liveness experience and inspire design. We share the interest in liveness with media studies that has identified the attractiveness of "live" in the context of traditional TV and radio broadcasts, which in turn led us to the elaborated conceptualisation described in this paper. We also share the interest with emerging research in HCI that identifies liveness experiences, e.g. as part of interactive art and performance. But since the use of the term "liveness" seems scattered in this area, we suggest a comprehensive approach that articulates media conceptions in a broad sense.

This paper presents an initial user study of TransLive, a system connecting people with their cherished places. The findings support our idea of combining personalized mobile webcasting and its materialization in an aesthetical and ambient way in the home. Our study underscores experience of immediacy and appearance of the unexpected as compelling. It extends the understanding of liveness by arguing for its experience in conjunction with sporadic engagement and authenticity work. We also identified how the experience of transcendence blends into liveness, which points to a potential new direction in design.

In all, we suggest that research in HCI, which e.g. addresses the emergence of real time video applications, benefits from elaboration of liveness in media theory for two reasons. First, liveness captures important aspects of a "magical" experiential quality. Second, it supports forming a domain and research community including traditional media and new variations of them, which draw on mobile technology and user-generated content. An alternative would be to scale down the scope of conceptualisations. This however would lead us to define the "magic" as being "real time". Such articulation could account for important aspects of the favoured experiences but risk being too abstract to inspire new design. At the same time, we also need to acknowledge the need to revisit and extend the concept of liveness.

\section{REFERENCES}

1. Al-Ani, B., Mark, G., Chung, J., and Jones, J. The Egyptian Blogosphere: A Counter-narrative of the Revolution. In Proc. CSCW'12, ACM (2012), 17-26.

2. Auslander, P. Liveness: Performance in a mediatized culture. Routledge, 2008.

3. Bachelard, G. The Poetics of Space. Beacon Press,1994.

4. Bizzocchi, J. The magic window: the emergent aesthetics of high-resolution large-scale video display. . In Proc. ICPS'03, (2003), 1-4.

5. Bizzocchi, J. Ambient Video. In Proc.ACE'06, (2006)

6. Bizzocchi, J. Winterscape and ambient video: an intermedia border zone. In Proc.MM'08, ACM (2008), 949-952. 
7. Bowers, J., Taylor, R., Hook, J. et al. HCI: Humancomputer Improvisation. In Proc.DIS'14, ACM (2014), 203-206.

8. Brown, B., Reeves, S., and Sherwood, S. Into the Wild: Challenges and Opportunities for Field Trial Methods. In Proc.CHI'11, ACM (2011), 1657-1666.

9. Creswell, J.W. Qualitative inquiry and research design: Choosing among five approaches. Sage publications, 2012.

10. Csikszentmihalyi, M. and Halton, E. The Meaning of Things: Domestic Symbols and the Self. Cambridge University Press, 1981.

11. Engström, A. and Perry, M. "Liveness" in live TV: production, experience and future design. In Proc. CHI'11 EA, ACM Press (2011).

12. Friederichs-Büttner, G., Walther-Franks, B., and Malaka, R. An Unfinished Drama: Designing Participation for the Theatrical Dance Performance Parcival XX-XI. In Proc.DIS'12, ACM (2012), 770 778.

13. Gaver, W., Boucher, A., Law, A., et al. Threshold Devices: Looking out from the Home. In Proc.CHI'08, ACM (2008), 1429-1438.

14. Gaver, W. What should we expect from research through design? In Proc. CHI '12, (2012), 937 - 946.

15. Gaver, W., Bowers, J., Boehner, K., et al. Indoor weather stations: investigating a ludic approach to environmental HCI through batch prototyping. In Proc.CHI'13, ACM (2013), 3451-3460.

16. Gaver, W. The video window: my life with a ludic system. Personal and Ubiquitous Computing 10, 2-3 (2005), 60-65.

17. Harper, R. The Connected Home: The Future of Domestic Life: The Future of Domestic Life. Springer, 2012.

18. Hook, J., McCarthy, J., Wright, P., and Olivier, P. Waves: Exploring Idiographic Design for Live Performance. In Proc.CHI'13, ACM (2013),2969-2978.

19. Hook, J., Schofield, G., Taylor, R., et al. Exploring HCI's Relationship with Liveness. In Proc. CHI'12 EA, ACM (2012), 2771-2774.

20. Jacobs, R., Benford, S., Selby, M., et al. A Conversation Between Trees: What Data Feels Like in the Forest. In Proc.CHI'13, ACM (2013), 129-138.

21. Joshi, N., Kar, A., and Cohen, M. Looking at You: Fused Gyro and Face Tracking for Viewing Large Imagery on Mobile Devices. In Proc.CHI'12, ACM (2012), 2211-2220.

22. Juhlin, O., Engström, A., and Reponen, E. Mobile Broadcasting: The Whats and Hows of Live Video As a Social Medium. In Proc.MobileHCI'10, ACM (2010), 35-44.

23. Juhlin, O., Zoric, G., Engström, A., et al. Video interaction: a research agenda. Personal and Ubiquitous Computing 18, 3 (2014), 685-692.
24. Katz, J. How emotions work. University of Chicago Press, 1999.

25. Kirk, D., Sellen, A., Harper, R., et al. Understanding Videowork. In Proc.CHI'07, (2007), 61-70.

26. Leong, T.W. and Wright, P.C. Revisiting Social Practices Surrounding Music. In Proc.CHI'13, ACM (2013), 951-960.

27. MacNeill, M. Networks: producing Olympic ice hockey for a national television audience. Sociology of Sport Journal 13, 2 (1996), 103-124.

28. Maleki, M.M., Woodbury, R.F., and Neustaedter, C. Liveness, Localization and Lookahead: Interaction Elements for Parametric Design. In Proc.DIS'14, ACM (2014), 805-814.

29. Maloney, J.H. and Smith, R.B. Directness and Liveness in the Morphic User Interface Construction Environment. In Proc.UIST'95, ACM (1995), 21-28.

30. Massimi, M. and Neustaedter, C. Moving from Talking Heads to Newlyweds: Exploring Video Chat Use During Major Life Events. In Proc.DIS'14, ACM (2014), 43-52.

31. Mughal, M.A., Wang, J., and Juhlin, O. Juxtaposing Mobile Webcasting and Ambient Video for Home Décor. In Proc.MUM' 14, ACM (2014), 151-159.

32. Patton, M.Q. Qualitative evaluation and research methods. SAGE Publications, inc, 1990.

33. Reeves, S., Benford, S., O'Malley, C., and Fraser, M. Designing the Spectator Experience. In Proc.CHI'05, ACM (2005), 741-750.

34. Scannell, P. Radio, Television, and Modern Life: a phenomenological approach. (1996).

35. Shirky, C. Here comes everybody: The power of organizing without organizations. Penguin, 2008.

36. Thompson, J.B. Media and modernity: A social theory of the media. John Wiley \& Sons, 1995.

37. Unander-Scharin, C., Unander-Scharin, A., and Höök, K. The Vocal Chorder: Empowering Opera Singers with a Large Interactive Instrument. In Proc.CHI'14, ACM (2014), 1001-1010.

38. Vihavainen, S., Mate, S., Liikkanen, L., and Curcio, I. Video As Memorabilia: User Needs for Collaborative Automatic Mobile Video Production. In Proc.CHI'12, ACM (2012), 651-654.

39. Weilenmann, A., Hillman, T., and Jungselius, B. Instagram at the Museum: Communicating the Museum Experience Through Social Photo Sharing. In Proc.CHI'13, ACM (2013), 1843-1852.

40. Ylirisku, S., Lindley, S., Jacucci, G., et al. Designing web-connected physical artefacts for the 'aesthetic' of the home. In Proc. CHI '13, ACM (2013), 909.

41. Zimmerman, J., Forlizzi, J., and Evenson, S. Research through design as a method for interaction design research in HCI. In Proc. CHI'07, ACM (2007), 493502

42. Instant Peeping. http://instantpeeping.dareville.com/ 